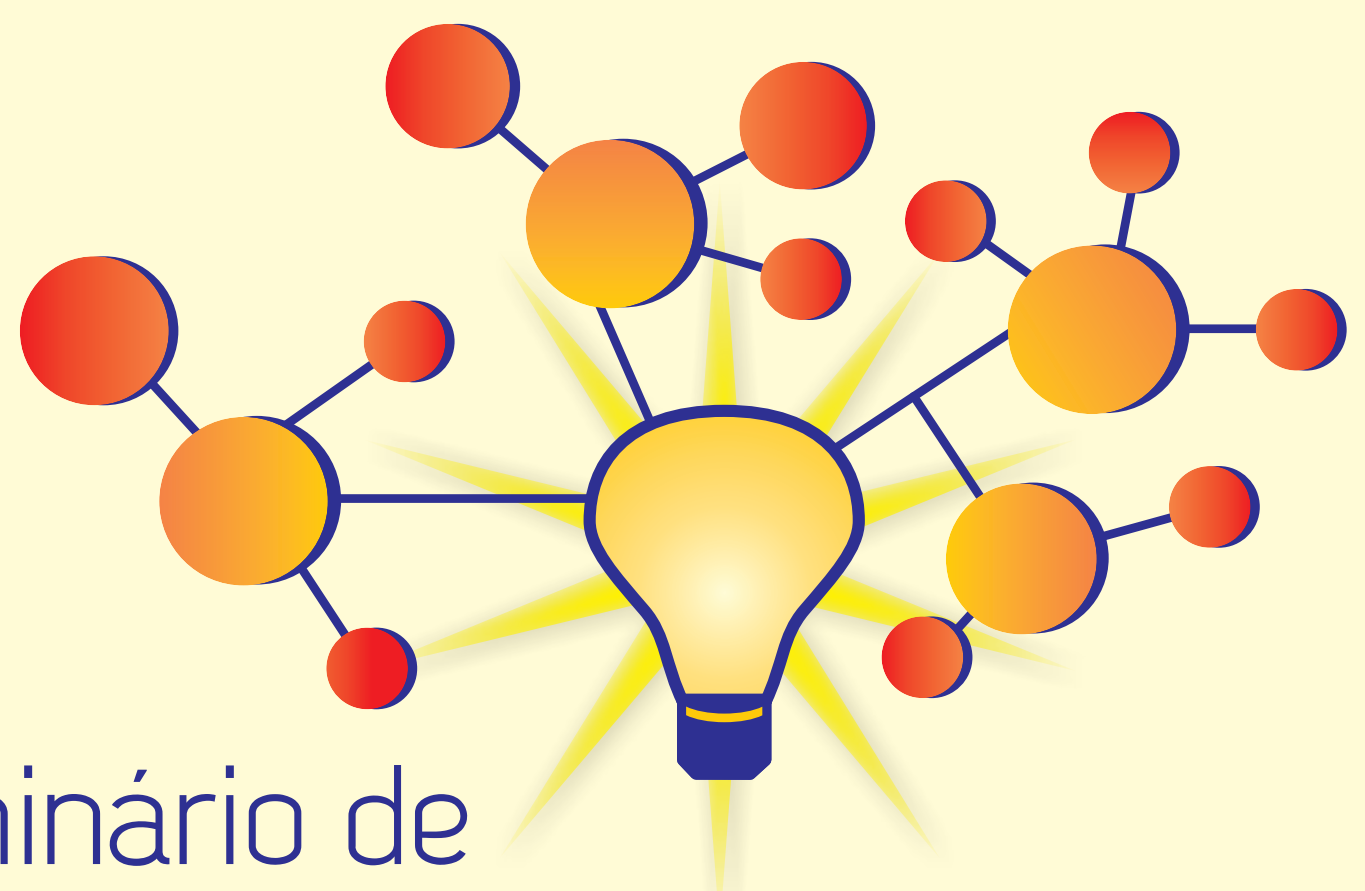

20० Seminário de

Iniciação Científica e

$4^{\circ}$ Seminário de Pós-graduação

da Embrapa Amazônia Oriental

21 a 23 de setembro

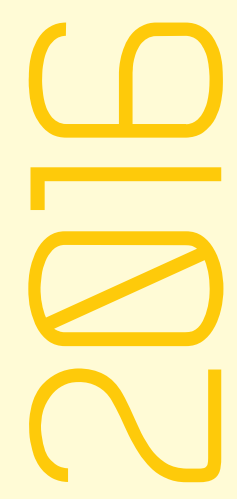




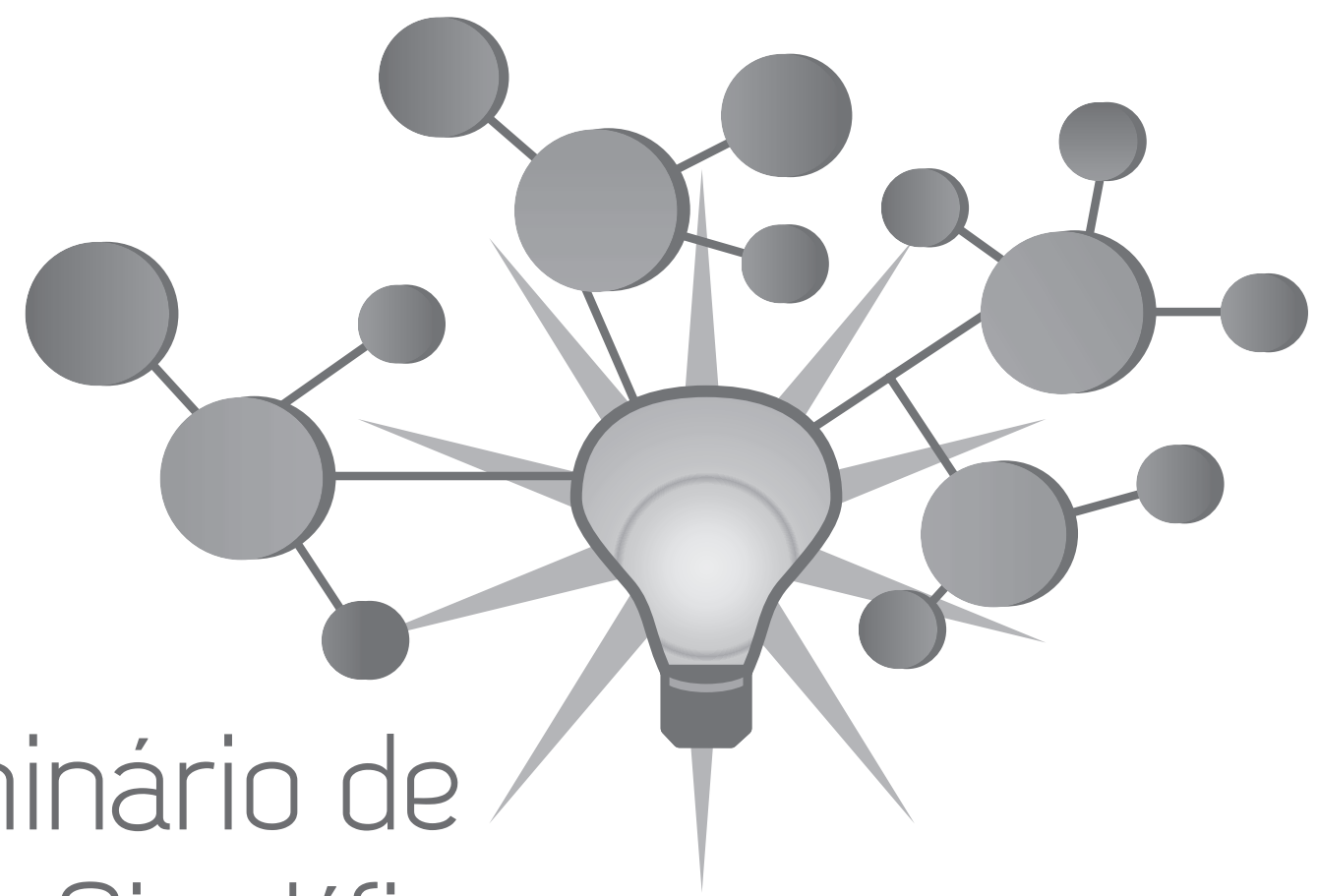

\section{Seminário de \\ Iniciação Científica e}

\section{$4^{\circ}$ Seminário de Pós-graduação da Embrapa Amazônia Oriental}
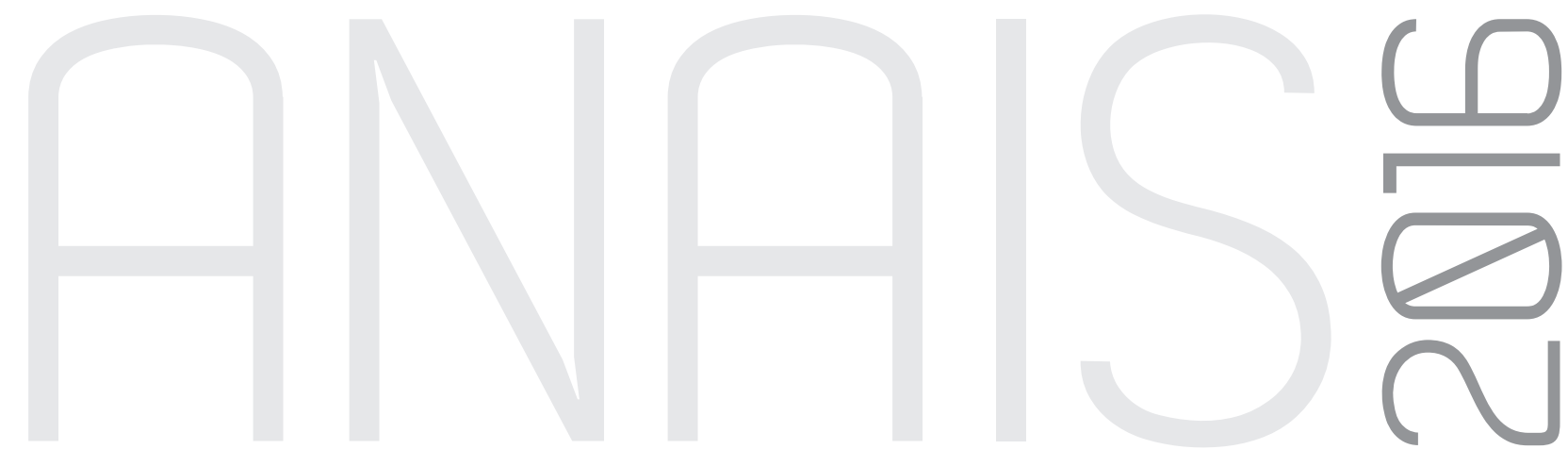

21 a 23 de setembro 


\title{
CARACTERIZAÇÃO MORFOLÓGICA DE INFLORESCÊNCIAS EM ACESSOS DE Oenocarpus bataua MART.
}

\author{
Alynne Regina N. Alves Maciel ${ }^{1}$, Maria do Socorro Padilha de Oliveira ${ }^{2}$, Camila Pinto Brandão ${ }^{3}$ \\ ${ }^{1}$ Bolsista CNPq da Embrapa Amazônia Oriental, Laboratório de Fitomelhoramento, alynnemaciel10@gmail.com \\ 2 Pesquisadora Embrapa Amazônia Oriental, Laboratório de Fitomelhoramento, socorro- \\ padilha.oliveira@cpatu.embrapa.br \\ ${ }^{3}$ Estagiária da Embrapa Amazônia Oriental, Laboratório de Fitomelhoramento, brandaopcamila@gmail.com
}

Resumo: Caracterizaram-se morfologicamente inflorescências de acessos de $O$. bataua conservados no Banco Ativo de Germoplasma da Embrapa Amazônia Oriental. Para tanto, foram retiradas dez ráquilas ao acaso por inflorescência de plantas representantes de 19 acessos. Nas amostras retiradas foram caracterizadas para treze caracteres. Os dados obtidos foram digitados em planilha Excel e submetidos às análises de estatística descritiva. Os 19 acessos apresentaram variação para todos os caracteres, com comprimento médio da ráquila de $85,64 \mathrm{~cm}$, onde $33,31 \mathrm{~cm}$ contêm apenas flores masculinas, $13,17 \mathrm{~cm}$ não apresentaram nenhum tipo de flor e em 39,16 cm ocorrem flores na disposição de duas masculinas para uma feminina. Cada ráquila teve, em média, 38 flores femininas e 250 masculinas, podendo atingir até 71 flores femininas, com variações para o tamanho das flores femininas e masculinas. A coloração predominante das flores foi o amarelo claro (7.5 YR; 2,5Y; 2.5YR; 5Y) havendo concordância para as cores da ráquila e da flor feminina com seis gradações para ambas, e sete gradações de amarelo para flores masculinas. Portanto, os acessos de 0 . bataua caracterizados possuem diferenças para caracteres de inflorescências, onde se pode evidenciar indivíduos com um maior potencial produtivo.

Palavras-chave: Patauá, palmeira, flores, variações, potencial produtivo

\section{Introdução}

O Patauá como é vulgarmente conhecido Oenocarpus bataua, é uma palmeira nativa da região Amazônia, de ocorrência em países da América Central (OLIVEIRA; OLIVEIRA, 2015), sendo considerada semi domesticada ou não domesticada (CLEMENT, 2001). É uma espécie monocaule, com folhas dispostas em espiral, fácil de ser notada por seu grande porte. Da polpa de seus frutos se 
obtém a bebida denominada patauá, alimento muito apreciado pelas famílias tradicionais da região Amazônica, de onde também se obtém óleo similar ao de azeite de oliva, o qual já foi amplamente difundido (OLIVEIRA; OLIVEIRA, 2015). Logo, essa palmeira possui grande potencial para ser explorado como produto não madeireiro, em suas populações naturais e até cultivado em escala comercial.

Na Embrapa Amazônia Oriental há um Banco de Germoplasma de patauá contendo acessos coletados em vários locais da Amazônia e que precisam ser caracterizados e avaliados para diferentes usos. A caracterização morfológica é a mais usada por gerar informações sobre a descrição e a classificação do matéria e na discriminação de caracteres mais importantes (OLIVEIRA, 2001).

Este trabalho teve por objetivo caracterizar morfologicamente inflorescências em acessos de O. bataua conservados no Banco Ativo de Germoplasma da Embrapa Amazônia Oriental.

\section{Material e Métodos}

No período de agosto/2015 a julho/2016 foram caracterizadas inflorescências ( $n=1$ a 3) recém abertas de plantas representantes de 19 acessos de patauá conservados no Banco Ativo de germoplasma (№ 002/2008 - Processo 02001.000104/2013-62) da Embrapa Amazônia Oriental, Belém, PA.

De cada inflorescência foram retiradas ao acaso dez ráquilas, as quais foram identificadas, colocadas em saco de papel e transportadas até o Laboratório de Fitomelhoramento dessa instituição para serem mensurados treze caracteres, que foram: comprimento da ráquila (CR), distância da primeira flor feminina a inserção da ráquila na ráquis (DPFF) e extensão das flores masculinas ao longo da ráquila (DFM); comprimento (CFF) e diâmetro da flor feminina (DFF) e comprimento do estigma (CE); diâmetro da flor masculina (DFM); comprimento da flor (CFM), da antera (CA) e do filete da flor masculina (CF), obtidos em $\mathrm{mm}$; e número de flores femininas (NFF) e de masculinas (NFM) e de estames (NE). Caracterizou-se também a cor da ráquila (CorR), da flor feminina (CorFF) e da masculina (CorFM) com base na carta de cores (MUNSELL COLOR CHARTS, 1977). 


\section{Seminário de Iniciação Científica e 4 Seminário de Pós-graduação}

da Embrapa Amazônia Oriental

21 a 23 de setembro de 2016, Belém, PA.

Os dados obtidos foram organizados em planilhas do Excel e submetidos às analises de estatística descritiva.

\section{Resultados e Discussão}

No período de estudo foram coletadas amostras de ráquilas em 27 inflorescências nos 19 acessos. O acesso 12003 emitiu três inflorescências, cinco acessos (12038, 12033, 12034, 12024, 12001, 12028) produziram duas inflorescências, os demais uma. Os acessos apresentaram grande variação para todos os caracteres, com média $85,64 \mathrm{~cm}$ para o comprimento da ráquila (CR), podendo alcançar até 115,50 cm (Tabela 1). Desse comprimento médio 33,31 cm apresentou apenas flores masculinas, em 13,17 cm não ocorreu nenhum tipo de flor (DPFF) e em 39,16 cm ocorreram duas flores masculinas ladeando uma feminina. Cada ráquila teve, em média, 38 flores femininas e 250 masculinas, variando de 1 a 71 flores femininas e de 195 a 369 masculinas. Resultados semelhantes foram encontrados por Núñez et al. (2015) ao avaliarem inflorescências de patauazeiro na Amazônia colombiana. As flores femininas e masculinas apresentaram tamanhos distintos. Mas, o destaque deu-se para o número de estames (NE) que, na maioria dos acessos, foi de 12 estames. No acesso 12003 o NE variou de 9 a 15 estames, enquanto nos acessos 62004, 62011, 62013, 62016 foi de 9 estames, mostrando-se um caráter discriminatório entre os acessos.

A cor predominante das flores foi o amarelo claro (2.5YR, 7.5YR, 5Y, 2.5Y) havendo concordância para as cores da ráquila e da flor feminina em seis gradações $2.5 Y R$ 8/2, 7.5YR8/4, 5Y 8/4, 2.5Y 8/4, 7.5 YR 8/6, 7.5 YR 8/2, e sete gradações de amarelo para flores masculinas 7.5YR 8/6, 7.5YR 7/4, 2.5 Y8/8, 5Y 8/6, 5Y 3/6, 7.5YR 8/2, 7.5 YR 8/4. 


\section{0ㅇ Seminário de Iniciação Científica e 4o Seminário de Pós-graduação da Embrapa Amazônia Oriental 21 a 23 de setembro de 2016, Belém, PA.}

Tabela 1. Médias, valores máximos e mínimos para13 caracteres de inflorescência caracterizados em 19 acessos de Oenocarpus bataua Mart. conservados na Embrapa Amazônia Oriental, Belém, PA.

\begin{tabular}{|c|c|c|c|c|c|c|c|c|c|c|c|c|c|}
\hline Acesso & $\begin{array}{c}\text { CR } \\
(\mathrm{cm})\end{array}$ & $\begin{array}{l}\text { DPFF } \\
(\mathrm{cm})\end{array}$ & $\begin{array}{l}\text { DFM } \\
(\mathrm{cm})\end{array}$ & $\begin{array}{l}\text { FFR } \\
\text { (№) }\end{array}$ & $\begin{array}{l}\text { FMR } \\
(\mathrm{n}-)^{2}\end{array}$ & $\begin{array}{c}\text { CFF } \\
(\mathrm{mm})\end{array}$ & $\begin{array}{c}\text { DFF } \\
(\mathrm{mm})\end{array}$ & $\begin{array}{c}\text { CE } \\
(\mathrm{mm})\end{array}$ & $\begin{array}{l}\text { CFM } \\
(\mathrm{mm})\end{array}$ & $\begin{array}{r}\text { DFM } \\
(\mathrm{mm})\end{array}$ & $\begin{array}{l}\text { NE } \\
(n \div 0)\end{array}$ & $\begin{array}{c}\text { CF } \\
(\mathrm{mm})\end{array}$ & $\begin{array}{c}\mathrm{CA} \\
(\mathrm{mm})\end{array}$ \\
\hline 12003 & 81,38 & 9,07 & 28,93 & 66,32 & 302,10 & 4,81 & 5,72 & 3,46 & 6,33 & 3,78 & 15 & 3,01 & 3,38 \\
\hline 12010 & 115,50 & 16,20 & 35,80 & 68,40 & 285,80 & 4,39 & 5,82 & 2,94 & 7,82 & 3,61 & 12 & 3,06 & 2,35 \\
\hline 12038 & 87,18 & 13,10 & 36,85 & 45,20 & 226,30 & 4,55 & 5,17 & 3,35 & 6,43 & 3,89 & 12 & 2,81 & 3,51 \\
\hline 12016 & 107,00 & 23,12 & 32,58 & 56,50 & 223,40 & 5,49 & 5,69 & 3,42 & 7,37 & 3,73 & 12 & 2,85 & 3,97 \\
\hline 12033 & 82,91 & 12,11 & 36,41 & 57,20 & 211,40 & 5,36 & 5,69 & 3,85 & 6,48 & 3,77 & 12 & 2,82 & 3,69 \\
\hline 12034 & 75,45 & 12,27 & 37,82 & 46,45 & 231,40 & 4,85 & 4,67 & 3,80 & 6,27 & 3,59 & 12 & 2,85 & 3,37 \\
\hline 12017 & 93,47 & 19,23 & 30,96 & 45,90 & 194,80 & 4,65 & 5,59 & 3,45 & 6,18 & 2,62 & 12 & 2,32 & 2,95 \\
\hline 12024 & 79,04 & 10,66 & 40,13 & 33,40 & 217,40 & 5,13 & 4,22 & 2,95 & 4,89 & 3,42 & 12 & 2,83 & 3,14 \\
\hline 12001 & 72,70 & 11,18 & 31,19 & 21,55 & 212,60 & 4,23 & 4,21 & 3,28 & 5,86 & 3,77 & 12 & 2,72 & 3,51 \\
\hline 12013 & 108,55 & 22,85 & 48,20 & 32,70 & 222,40 & 4,51 & 6,46 & 3,69 & 7,36 & 3,93 & 12 & 2,80 & 3,61 \\
\hline 22023 & 95,07 & 15,19 & 50,60 & 31,80 & 217,60 & 5,19 & 4,95 & 3,66 & 5,49 & 4,75 & 12 & 3,49 & 4,01 \\
\hline 12002 & 73,64 & 10,64 & 29,83 & 36,45 & 213,10 & 5,12 & 5,83 & 4,35 & 6,78 & 3,54 & 12 & 2,93 & 3,28 \\
\hline 12026 & 58,02 & 5,95 & 23,48 & 22,80 & 195,00 & 4,91 & 5,08 & 3,92 & 6,49 & 3,66 & 12 & 2,80 & 3,80 \\
\hline 12028 & 106,80 & 16,61 & 57,20 & 70,45 & 242,90 & 4,82 & 5,24 & 3,67 & 6,84 & 3,93 & 12 & 2,69 & 3,84 \\
\hline 12032 & 84,22 & 13,13 & 32,12 & 41,50 & 221,60 & 4,98 & 5,04 & 3,97 & 6,56 & 3,99 & 12 & 2,84 & 4,19 \\
\hline 62004 & 75,98 & 8,56 & 9,65 & 15,70 & 334,40 & 5,52 & 6,61 & 4,66 & 4,78 & 2,24 & 9 & 2,30 & 2,03 \\
\hline 62011 & 83,25 & 11,34 & 7,53 & 6,80 & 320,40 & 5,44 & 7,57 & 4,58 & 4,77 & 2,84 & 9 & 2,53 & 2,48 \\
\hline 62013 & 69,89 & 8,84 & 4,08 & 4,30 & 324,20 & 5,07 & 7,10 & 4,13 & 4,19 & 2,59 & 9 & 2,44 & 2,06 \\
\hline 62016 & 77,22 & 10,25 & 59,60 & 1,00 & 369,40 & 5,25 & 5,90 & 4,31 & 4,37 & 2,71 & 9 & 2,65 & 2,04 \\
\hline Média & 85,64 & 13,17 & 33,31 & 37,07 & 250,85 & 4,96 & 5,61 & 3,76 & 6,07 & 3,49 & 11,47 & 2,78 & 3,22 \\
\hline Max & 115,50 & 23,12 & 59,60 & 70,45 & 369,40 & 5,52 & 7,57 & 4,66 & 7,82 & 4,75 & 14,00 & 3,49 & 4,19 \\
\hline Min & 58,02 & 5,95 & 4,08 & 1,00 & 194,80 & 4,23 & 4,21 & 2,94 & 4,19 & 2,24 & 9,00 & 2,30 & 2,03 \\
\hline
\end{tabular}

CR: comprimento da ráquila; DPFF: distância da1 flor feminina a inserção da ráquila; DFM: disposição das flores masculinas na ráquila; FF: $\mathrm{n}$ o de flores femininas; FM: $\mathrm{n}$ o de flores masculinas; LFF: largura da flor feminina; DFF: diâmetro da flor feminina; CE: comprimento do estigma; CFM: comprimento da flor masculina; LFM: largura da flor masculina; NE: número de estames por flor masculina; CF: comprimento do filete; CA: comprimento da antera.
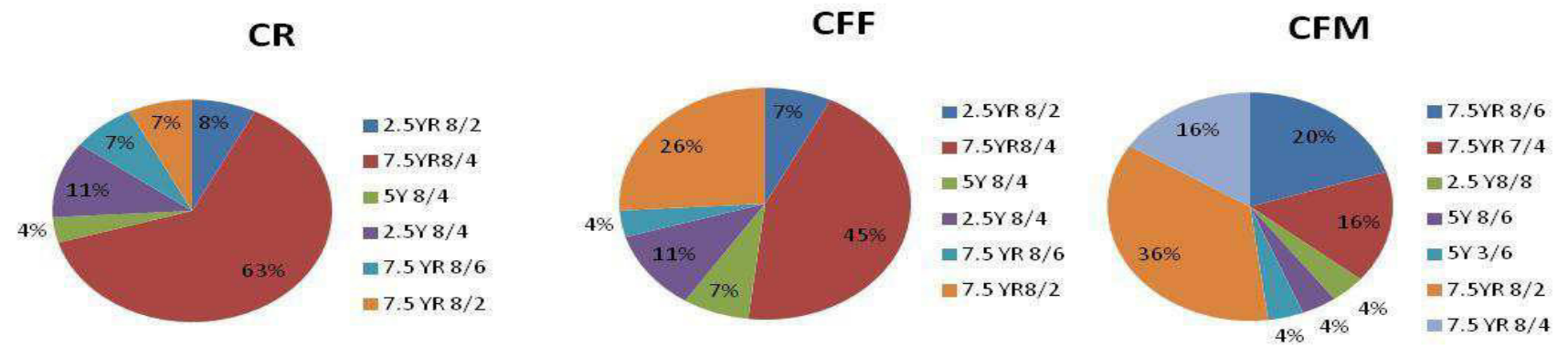

Figura 1. Variação de cores da ráquila (CR), da flor feminina (CFF) e flor masculina (CFM) em inflorescências recém abertas de acessos de Oenocarpus bataua Mart. conservados na Embrapa Amazônia Oriental, Belém, PA. 


\section{Conclusão}

Os acessos de $O$. bataua caracterizados possuem diferenças para caracteres de inflorescências, onde se pode evidenciar indivíduos com um maior potencial produtivo.

\section{Agradecimentos}

Ao CNPq pela concessão de bolsa e aos técnicos do laboratório de fitomelhoramento, Joel Pinheiro e Claudemir Araújo, pelo auxílio na coleta dos dados.

\section{Referências Bibliográficas}

CLEMENT, C. R. Melhoramento de espécies nativas. In: NASS, L. L.; VALOIS, A. C. C.; MELO, I. S. de; INGLIS, M. C. V. Recursos genéticos e melhoramento de plantas. Rondonópolis: Fundação MT, 2001. p. 423-441.

MUNSELL COLOR CHARTS. Munsell Color Charts for Plant Tissues. New York, 1977.

NÚÑEZ, L. A.; ISAZA, C.; GALEANO G. Ecología de la polinización de tres especies de oenocarpus (arecaceae) simpátricas en la amazonia colombiana. Revista de Biologia Tropical, v. 63, n. 1, p. 35-55, mar. 2015.

OLIVEIRA, M. do S. P. Caracterização morfológica de frutos em acessos de tucumanzeiro (Astrocaryum vulgare Mart.). In: SIMPÓSIO DE RECURSOS GENÉTICOS PARA AMÉRICA LATINA E CARIBE, 3., 2001, Londrina. Anais... Londrina: IAPAR, 2001. p. 351.

OLIVEIRA, M. do S. P. de; OLIVEIRA, N. P. de. Patauá. In: LOPES, R.; OLIVEIRA, M. S. P.; CAVALLARI, M. M.; BARBIERI, R. L.; CONCEIÇÃO, L. D. H. C. S. Palmeiras Nativas do Brasil. Brasília, DF: Embrapa, 2015. p. 309-338. 